\title{
Enzymatic function of hemoglobin as a nitrite reductase that produces NO under allosteric control
}

\author{
Zhi Huang, ${ }^{1,2}$ Sruti Shiva, ${ }^{1}$ Daniel B. Kim-Shapiro,,3,4 Rakesh P. Patel,5 Lorna A. Ringwood,1 \\ Cynthia E. Irby, ${ }^{6}$ Kris T. Huang, ${ }^{3,4}$ Chien Ho, ${ }^{7}$ Neil Hogg, ${ }^{8}$ Alan N. Schechter, ${ }^{2}$ and Mark T. Gladwin ${ }^{1,6}$ \\ ${ }^{1}$ Vascular Therapeutics Section, Cardiovascular Branch, National Heart, Lung and Blood Institute, and \\ 2Laboratory of Chemical Biology, National Institute of Diabetes, Digestive and Kidney Diseases, NIH, Bethesda, Maryland, USA \\ ${ }^{3}$ Department of Physics and ${ }^{4}$ Department of Biomedical Engineering, Wake Forest University, Winston-Salem, North Carolina, USA \\ ${ }^{5}$ Department of Pathology and Center for Free Radical Biology, University of Alabama at Birmingham, Birmingham, Alabama, USA \\ ${ }^{6}$ Critical Care Medicine Department, Clinical Center, NIH, Bethesda, Maryland, USA. ${ }^{7}$ Department of Biological Sciences, Carnegie Mellon University, \\ Pittsburgh, Pennsylvania, USA. ${ }^{8}$ Department of Biophysics and Free Radical Research Center, Medical College of Wisconsin, Milwaukee, Wisconsin, USA.
}

\begin{abstract}
Hypoxic vasodilation is a fundamental, highly conserved physiological response that requires oxygen and/or $\mathrm{pH}$ sensing coupled to vasodilation. While this process was first characterized more than 80 years ago, the precise identity and mechanism of the oxygen sensor and mediators of vasodilation remain uncertain. In support of a possible role for hemoglobin $(\mathrm{Hb})$ as a sensor and effector of hypoxic vasodilation, here we show biochemical evidence that $\mathrm{Hb}$ exhibits enzymatic behavior as a nitrite reductase, with maximal NO generation rates occurring near the oxy-to-deoxy (R-to-T) allosteric structural transition of the protein. The observed rate of nitrite reduction by $\mathrm{Hb}$ deviates from second-order kinetics, and sigmoidal reaction progress is determined by a balance between 2 opposing chemistries of the heme in the R (oxygenated conformation) and T (deoxygenated conformation) allosteric quaternary structures of the $\mathrm{Hb}$ tetramer - the greater reductive potential of deoxyheme in the $\mathrm{R}$ state tetramer and the number of unligated deoxyheme sites necessary for nitrite binding, which are more plentiful in the $T$ state tetramer. These opposing chemistries result in a maximal nitrite reduction rate when $\mathrm{Hb}$ is $40-60 \%$ saturated with oxygen (near the $\mathrm{Hb} \mathrm{P}_{50}$ ), an apparent ideal set point for hypoxiaresponsive NO generation. These data suggest that the oxygen sensor for hypoxic vasodilation is determined by $\mathrm{Hb}$ oxygen saturation and quaternary structure and that the nitrite reductase activity of $\mathrm{Hb}$ generates $\mathrm{NO}$ gas under allosteric and $\mathrm{pH}$ control.
\end{abstract}

\section{Introduction}

Hypoxic vasodilation is a fundamental physiological response that ensures adequate oxygen delivery and blood buffering capacity (including $\mathrm{CO}_{2}$ elimination) to tissues under metabolic stress. This highly conserved physiological response requires oxygen and $\mathrm{pH}$ sensing coupled with vasodilation. While this process was first characterized more than 80 years ago $(1,2)$, the precise identity and mechanism of the oxygen sensor and mediators of vasodilation remain unknown $(3,4)$. From an oxygen-sensing standpoint, a situation in which the metabolic demand of a tissue exceeds oxygen delivery causes a divergence from the normal relationship between tissue oxygen consumption and vascular oxygen delivery. This creates an "error signal" that is characterized by an increasingly negative slope when venous $\mathrm{PaO}_{2}$ is plotted against oxygen consumption (4). While conventional wisdom suggests that this error signal is detected as a change in tissue or blood partial pressure of oxygen $\left(\mathrm{PO}_{2}\right)$ (i.e., the oxygen sensor detects $\left.\mathrm{PO}_{2}\right)$, recent studies have suggested that $\mathrm{Hb}$ oxygen saturation and $\mathrm{Hb}$ 's highly evolved allosteric conformational changes may subserve this oxy-

Nonstandard abbreviations used: $\mathrm{E}_{1 / 2}$, reduction (or redox) potential; $\mathrm{EPR}$, electron paramagnetic resonance; $\mathrm{Hb}$, hemoglobin; HbA, hemoglobin A; IHP, inositol hexaphosphate; $\mathrm{Mb}$, myoglobin; NEM, N-ethylmaleimide; $\mathrm{PO}_{2}$, partial pressure of oxygen. Conflict of interest: The authors have declared that no conflict of interest exists.

Citation for this article: J. Clin. Invest. 115:2099-2107 (2005).

doi:10.1172/JCI24650. gen-sensor function (5-13). Such allosteric changes have been associated with the release of red blood cell ATP (5-8), the formation of S-nitrosothiols from S-nitrosated $\mathrm{Hb}(9,10)$, and, recently, the reduction of blood nitrite to $\mathrm{NO}$ by $\mathrm{Hb}(11-14)$.

Early studies by Furchgott, Ignarro, and Murad demonstrated the ability of nitrite to activate soluble guanylate cyclase (sGC) and vasodilate aortic rings (15-17). However, the concentrations required for this effect in vitro (in the hundred- $\mu \mathrm{M}$ to $\mathrm{mM}$ range) largely precluded consideration of a role for nitrite in vivo in humans where circulating concentrations are typically less than $1 \mu \mathrm{M}$. We have reported the existence of arterial-to-venous gradients of plasma nitrite that increase with regional metabolic stress (18) and recently described a vasodilatory activity of nitrite at near physiological concentrations in vivo (11). This vasodilatory activity was associated with the conversion of nitrite to $\mathrm{NO}$ by deoxyHb, suggesting that $\mathrm{Hb}$ possesses a physiological nitrite reductase activity that might participate in hypoxic vasodilation. Indeed, Brooks in 1937 and Doyle and colleagues in 1981 characterized the reduction of nitrite to $\mathrm{NO}$ by deoxyHb $(19,20)$.

\section{Reaction 1}

$$
\begin{aligned}
& \text { Nitrite }\left(\mathrm{NO}_{2}^{-}\right)+\text {deoxyhemoglobin }\left(\mathrm{Fe}^{\prime \prime}\right)+\mathrm{H}^{+} \rightarrow \\
& \mathrm{NO}+\text { methemoglobin }\left(\mathrm{Fe}^{\prime \prime \prime}\right)+\mathrm{OH}^{-}
\end{aligned}
$$

We were struck by the potential physiological relevance of this reaction. The requirements for deoxyHb and protons in the reaction suggested a potential mechanism for oxygen and $\mathrm{pH}$ sensing. 
A
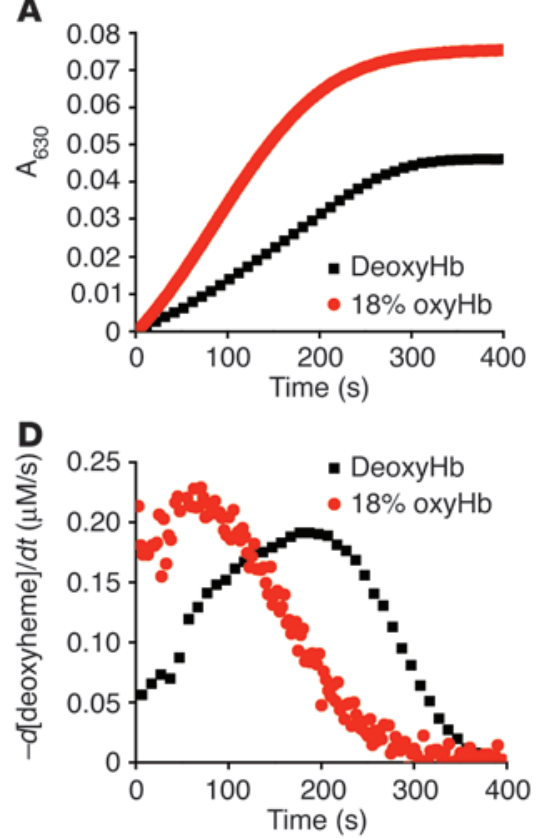

B

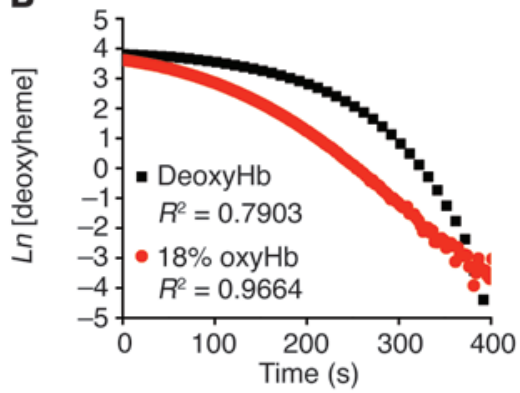

E

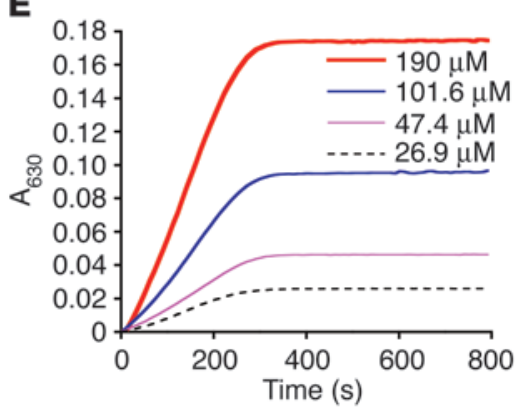

C

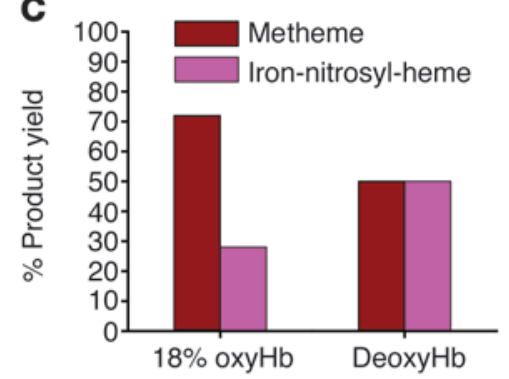

$\mathbf{F}$

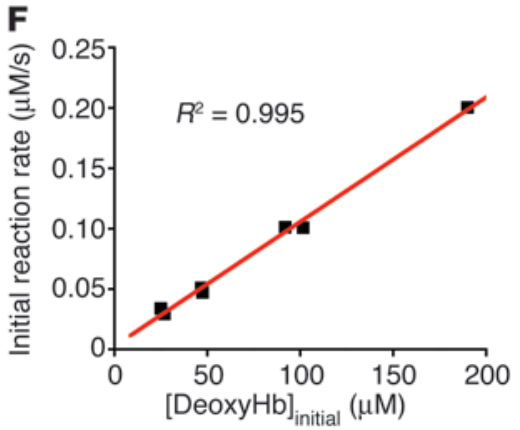

Figure 1

Reaction of nitrite with deoxyHb reveals deviation from first-order kinetics and equimolar product yields of metHb and iron-nitrosyl-Hb. (A) Progress of the nitrite- $\mathrm{Hb}$ reaction under conditions of excess nitrite $(10 \mathrm{mM}$ nitrite with $50 \mu \mathrm{M}$ heme $)$ monitored spectrophotometrically by formation of ferric hemes at $630 \mathrm{~nm}$ (baseline at $700 \mathrm{~nm}$ ) under anaerobic conditions or during partial oxygenation $(18 \%$ oxyHb). $50 \mu \mathrm{M} \mathrm{metHb} \mathrm{gives}$ $A_{630}$ of 0.12 with $10 \mathrm{mM}$ nitrite present. (B) The fit of the natural log of deoxyheme concentration versus time for conditions shown in $\mathbf{A}$, where $L n$ [deoxyheme] is the natural log of the deoxyheme concentration at each time point. The deoxyheme concentration at each time point was determined by spectral deconvolution. (C) Effects of oxygen leak on product yields in the nitrite-Hb reaction (calculated by spectral deconvolution for reactions in A). (D) Instantaneous rate of deoxyheme consumption over time during the course of a single reaction under the conditions in A. The instantaneous rate of deoxyheme consumption was found by negative change of deoxyheme concentration between 2 adjacent time points $(-d$ [deoxyheme]) over the time interval $(d t)$ where $d$ is change and $t$ is time. (E) Progress of the reaction of nitrite (10 $\mathrm{mM})$ with varying initial concentrations of deoxyheme monitored by the formation of metheme at $630 \mathrm{~nm}$. (F) Effect of varying the initial deoxyheme concentration (concentration of deoxyheme at the beginning of the reaction; [DeoxyHb] $]_{\text {initial }}$ ) on the initial rate of the reaction calculated from the data in $\mathbf{E}$. The initial reaction rate is the rate of ferric heme formation at the beginning of the reaction calculated as the average rate over the first 200 seconds using extinction coefficient of 3.4 at $630 \mathrm{~nm}$ (the rate of deoxyheme consumption is approximately twice as fast).

Furthermore, the 1-electron reduction of nitrite by ferrous deoxyheme suggests that redox properties of the heme may modulate this process. In support of these ideas, data from kinetic in vitro aortic ring bioassay experiments have demonstrated an apparent vasodilation threshold whereby nitrite- $\mathrm{Hb}$-dependent vasodilation is initiated at a $\mathrm{PO}_{2}$ approximating the $\mathrm{Hb} \mathrm{P}_{50}$ (11). The $\mathrm{P}_{50}$ represents the $\mathrm{PO}_{2}$ at which $\mathrm{Hb}$ is $50 \%$ saturated with oxygen. Importantly, as demonstrated in this study, the rate of nitrite reduction to $\mathrm{NO}$ gas by $\mathrm{Hb}$ is maximal when $\mathrm{Hb}$ is $50 \%$ saturated with oxygen. A maximal nitrite reductase activity occurring at the $\mathrm{Hb} \mathrm{P}_{50}$ would be ideal for hypoxic vasodilation, as the $\mathrm{Hb} \mathrm{P}_{50}$ is thermally, chemically, and allosterically modulated by surrounding tissue metabolism (21), and classical physiological studies of hypoxic vasodilation reveal an apparent hypoxic vasodilation threshold at 40-60\% Hb-oxygen saturation $(4,22)$.

\section{Results}

The nitrite reductase reaction revisited. The reaction of nitrite and deoxyHb has previously been described as a first-order reaction with respect to deoxyHb under conditions of excess nitrite, generating unbalanced product yields of $72 \%$ metHb and $28 \%$ iron-nitrosyl-Hb (19). However, based on Reaction 1, equivalent (50:50\%) product yields would be expected, with 1 mole of nitrite generating 1 mole of metheme and 1 mole of iron-nitrosyl-heme. We have examined this reaction under strict anaerobic conditions in the presence of excess nitrite (50 $\mu \mathrm{M}$ heme and $10 \mathrm{mM}$ nitrite) and observed an unexpected divergence from first-order kinetics and equimolar product yields of metheme and iron-nitrosyl-heme (Figure 1, A-C). However, with the introduction of trace oxygen (18\% oxyheme present at the beginning of the reaction), the rate of the reaction increases and more closely (although never exactly) approximates the first-order behavior observed in earlier studies (Figure 1, A and B). The nitrite reaction with partially oxygenated $\mathrm{Hb}$ also produces metheme and iron-nitrosyl-heme product yields consistent with levels observed in earlier studies (Figure 1C) (23). An oxygen leak would be expected to increase the yield of metheme due to the simultaneous reaction of nitrite with oxyheme as well as the reaction of $\mathrm{NO}$ (formed from the reaction of nitrite with deoxyheme) with oxyheme.

However, the deviation from first-order kinetics in the absence of oxygen and the effect of oxygen on increasing the reaction rate were unexpected (Figure 1, B and D). On initial inspection, under conditions in which nitrite concentration exceeded deoxyheme, the reaction of nitrite with deoxyheme (Figure 1A) appeared to display zero-order kinetics with respect to deoxyheme, as evidenced by a relatively constant rate throughout the process of the reaction even 
A

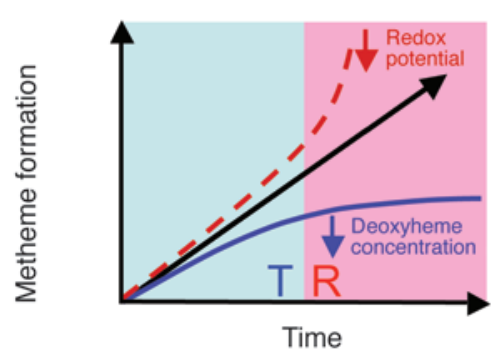

C

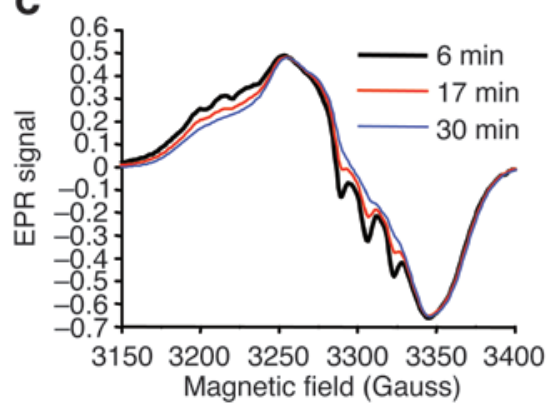

B

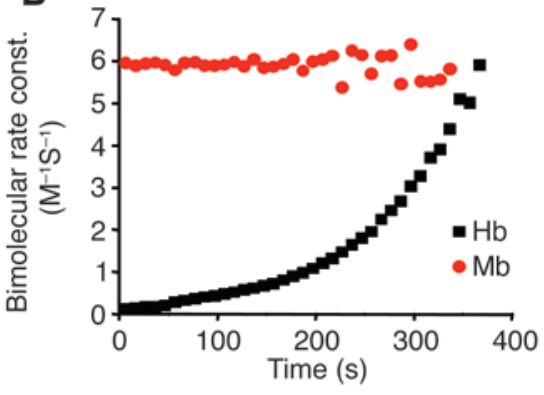

D

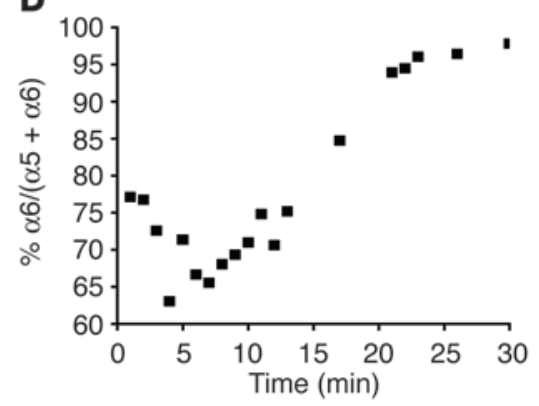

Figure 2

Sigmoidal reaction behavior of the nitrite-deoxyheme reaction occurs due to T-to- $\mathrm{R}$ allosteric quaternary transition of $\mathrm{Hb}$. (A) Model of the nitrite-deoxyHb reaction representing a balance between 2 opposing processes: (a) a decelerating reaction with T state deoxyheme due to depletion of deoxyheme available for reaction with nitrite because of conversion to metheme and iron-nitrosyl-heme (solid blue line); and (b) an accelerating reaction of nitrite with $\mathrm{R}$ state deoxyheme (dashed line). Solid black line with arrow represents the reaction process observed experimentally and is the balance of these 2 processes. (B) Apparent bimolecular rate constant over the time course of the anaerobic reaction of $\mathrm{Mb}(50 \mu \mathrm{M}$ heme) and $\mathrm{Hb}(50 \mu \mathrm{M}$ heme) with nitrite $(10 \mathrm{mM}$ with $\mathrm{Hb}$ and $2.5 \mathrm{mM}$ with $\mathrm{Mb}$ in heme concentrations). Bimolecular rate constant (const.) was obtained by dividing the instantaneous reaction rate of deoxyheme consumption by the concentration of deoxyheme and nitrite. (C) Initial (6 minutes), intermediate (17 minutes), and final (30 minutes) EPR spectra of iron-nitrosyl-heme monitored over the course of the nitrite-deoxyHb reaction $(100 \mu \mathrm{M}$ heme, $2.5 \mathrm{mM}$ nitrite) showing a transition from 5-coordinate (T state) $\alpha$ iron-nitrosyl-heme (with characteristic hyperfine splitting) to 6-coordinate (R state) heme geometry. The smaller EPR signals at earlier time points were normalized to that of the final time point in order to compare the spectral shape of the iron-nitrosyl-Hb signal. (D) T-to-R allosteric structural transition during the course of the nitrite-deoxyHb reaction, monitored by the percentage formation of 6-coordinate $\alpha$ iron-nitrosyl-heme relative to total $\alpha$ iron-nitrosyl-heme.

though the concentration of deoxyheme was continually decreasing (Reaction 1 and Figure 1, A and E). However, when we increased the initial concentration of deoxyHb (in the range of $26.9 \mu \mathrm{M}$ to $190 \mu \mathrm{M}$ ) we observed a linear increase in the initial reaction rate (Figure 1, E and F), a property consistent with first-order kinetics with respect to deoxyheme. A more careful examination of Figure $1, \mathrm{~A}$ and $\mathrm{D}$, suggests a sigmoidal reaction profile characterized by an increase and then a decrease in the rate, with the maximal rate occurring when approximately $50 \%$ of the deoxyheme is converted to metheme and iron-nitrosyl-heme. Thus, despite the decreasing concentration of deoxyheme available to react with nitrite during the course of the reaction, the reaction rate is able to increase until it reaches its maximum.

Increased rate of nitrite reduction by $R$ state $H b$. We hypothesized that the sigmoidal reaction profile observed is the sum of 2 opposing reactions of nitrite with deoxyheme in the 2 allosteric conformations of $\mathrm{Hb}$. As the reaction progresses, the reaction rate of nitrite with deoxyheme in $\mathrm{T}$ state tetramer decreases as deoxyheme is consumed. This is balanced by the accelerating reaction of nitrite with $\mathrm{R}$ state deoxyheme, as the concentration of this allosteric conformation increases with the formation of metheme and iron-nitrosyl-heme, which both stabilize R state tetramer (Figure 2A). This causes a T-to- $\mathrm{R}$ state allosteric transition to occur as metheme and iron-nitrosyl-heme levels increase in the $\mathrm{Hb}$ tetramer. We measured the bimolecular rate constant of the reaction of nitrite with deoxyHb and myoglobin $(\mathrm{Mb})$ over time and found that this parameter remained constant for monomeric $\mathrm{Mb}$ (Figure 2B). In contrast, the bimolecular rate constant increased exponentially $\left(R^{2}=0.998\right.$ for exponential fit) over the course of the reaction of tetrameric deoxyHb with nitrite, supporting the model in which the nitrite reductase activity of tetrameric deoxy $\mathrm{Hb}$ increases during the reaction time course (Figure $2 \mathrm{~B}$ ). We confirmed the presence of a T-to- $\mathrm{R}$ allosteric transition during the course of the reaction by monitoring the stabilization of the bond between the proximal histidine and the NO-liganded heme in the $\alpha$ chain of $\mathrm{Hb}$ by electron paramagnetic resonance (EPR) spectroscopy. As shown in Figure 2, C and D (experiment performed using $100 \mu \mathrm{M}$ deoxyheme and $2.5 \mathrm{mM}$ nitrite), as the reaction proceeded, the $\alpha$ iron-nitrosyl-heme transitioned from 5 ( $\mathrm{T}$ state) to 6 (R state) coordinated structure. This occurred because $\mathrm{T}$ state $\alpha$ iron-nitrosyl-heme exists in equilibrium between a 5-coordinate (histidine-to-heme bond disrupted) and 6-coordinate (histidine bond intact) species, while R state $\alpha$ iron-nitrosyl retains $100 \%$ 6-coordinate heme geometry (24). The percentage yield of each iron-nitrosylheme species during the reaction time course was similar to that observed by Hille et al. when NO buffer was titrated into deoxyHb solution (25). Also, the iron-nitrosyl-heme spectral change observed during the reaction process, as shown in Figure 2C, was similar to the spectral change observed during deoxygenation and reoxygenation of substoichiometric iron-nitrosyl- $\mathrm{Hb}$ (26). This confirms that as the deoxyheme is converted to metheme and iron-nitrosyl-heme during the reaction, the T-to-R allosteric transition does indeed occur.

It is likely that the accelerating rate of reaction of nitrite with $\mathrm{R}$ state $\mathrm{Hb}$ occurs due to the lower reduction potential (hence, a better electron donor) of the deoxyheme within the $\mathrm{R}$ state versus $\mathrm{T}$ state tetramers $(14,27)$. The initial rates of reaction of nitrite with $\mathrm{Mb}$ ( $\mathrm{R}$ state monomer), $\mathrm{N}$-ethylmaleimide-modified (NEM-modified) deoxyHb (R state stabilizing effect), native $\mathrm{Hb} \mathrm{A}$ ( $\mathrm{HbA}$ ), and inositol hexaphosphate-treated (IHP-treated) Hb (T state stabilizing) were compared to their published reduction potentials $\left(\mathrm{E}_{1 / 2} \mathrm{~s}\right)$ as averaged for the subunits to obtain overall values for the $\mathrm{Hb}$ tetramer $(50 \mu \mathrm{M}$ heme, $2.5 \mathrm{mM}$ nitrite) (Table 1 ) $(27,28)$. Similar to the initial rates plotted in Figure $1 \mathrm{~F}$, the initial rate of the reaction indicated in Table 1 was measured by 


\section{Table 1}

Initial rate of ferric heme formation in the anaerobic reaction of $50 \mu \mathrm{M}$ heme with $2.5 \mathrm{mM}$ nitrite correlates with the $E_{1 / 2}$ of various heme proteins

\begin{tabular}{lcc} 
Mutant & Reaction rate $(\mu \mathbf{M} / \mathbf{s})$ & $\mathbf{E}_{1 / 2}(\mathbf{m} / \mathbf{V})$ \\
Horse Mb & 0.1884 & 25 \\
HbA-NEM & 0.0915 & 45 \\
HbA & 0.0161 & 85 \\
HbA + IHP & 0.0054 & 135 \\
\hline
\end{tabular}

$R^{2}=1.000$, fitting to equation; $y=2.927 \times 10^{-5}+0.4844 e^{-x 26.62}$, where $y$ is the reaction rate and $x$ is $E_{1 / 2}$.

the average rate of metHb formation using the initial part of the reaction trace at $630 \mathrm{~nm}$. A higher rate of nitrite reduction correlated with a higher oxygen affinity or R state character and with lower $\mathrm{E}_{1 / 2} \mathrm{~S}$ for all of these conditions $\left(R^{2}=1.000\right.$ for exponential fit). These data are also consistent with the observed correlation between higher heme reduction potentials and the rates of alkaline reductive nitrosylation of metHb by NO, which forms ferrous $\mathrm{Hb}$ and nitrite; this reaction can be considered the reverse of the nitrite reductase reaction and is accelerated by higher heme $\mathrm{E}_{1 / 2}$ and alkaline $\mathrm{pH}$ (29). These data confirm that deoxyheme in the $\mathrm{R}$ state tetrameric $\mathrm{Hb}$ is a more facile nitrite reductase due to lowered heme $\mathrm{E}_{1 / 2}$.

It is clear from these data that the deviation from first-order kinetics in the reaction of nitrite with deoxyHb occurs because of the T-to-R allosteric transition. This was also confirmed by the first-order kinetics of molecules that are incapable of allosteric transition, such as $\mathrm{Mb}$ and $\beta$ chains of $\mathrm{Hb}$ ( $\mathrm{R}$ state tetramer only) and $\mathrm{Hb}$ with IHP and low $\mathrm{pH}$ (locked in T state). These data are shown for $\mathrm{Mb}$ in Figure 3, A and B, and for IHP at low $\mathrm{pH}$ and the $\beta$ chains of $\mathrm{HbA}$ in Figure 3, E and F.

For tetrameric $\mathrm{Hb}$ reacting anaerobically with nitrite, the reaction is essentially an allosteric autocatalytic reaction with a single nitrite reacting with one $\mathrm{T}$ state heme to generate a metheme and an iron-nitrosyl-heme, which by virtue of their R state stabilizing effects, allosterically lower the redox potential of 2-6 other hemes (dependent on inter- or intratetrameric iron-nitrosyl formation). This produces autocatalysis as $\mathrm{R}$ state hemes generate more $\mathrm{R}$ state hemes, exponentially decreasing $\mathrm{E}_{1 / 2}$ and increasing bimolecular rate constants during the course of the reaction (Figure $2 \mathrm{~B}$ ). Two recent papers have explored the reaction of nitrite with deoxyHb, coming to different conclusions. A study by Luchsinger and colleagues reported that this reaction yielded product ratios of metHb to iron-nitrosyl-Hb of $1: 1$ to $1: 6$, consistent with earlier studies by
A

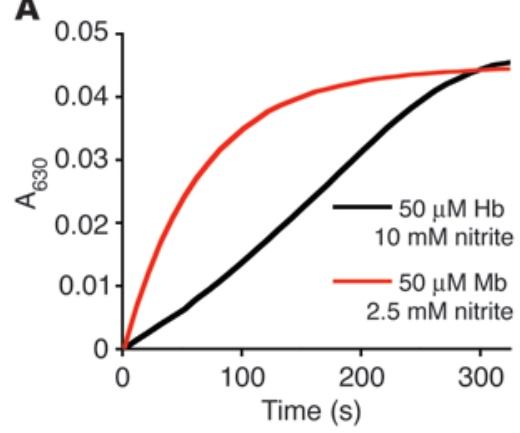

D

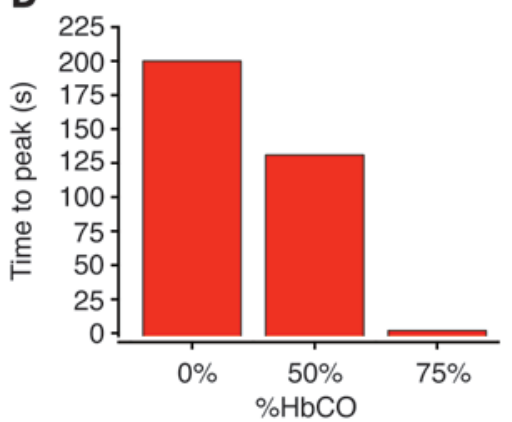

B
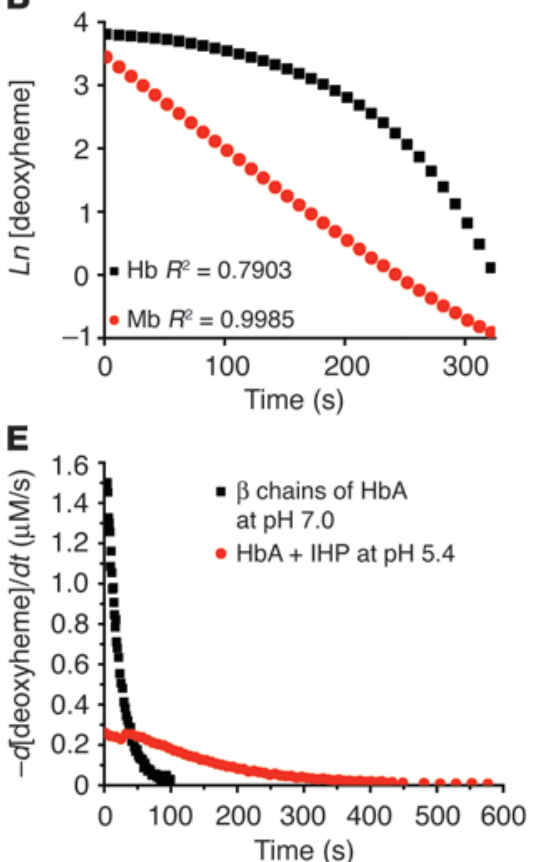

C

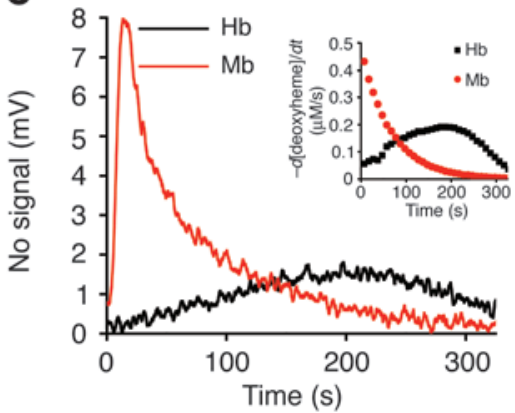

F

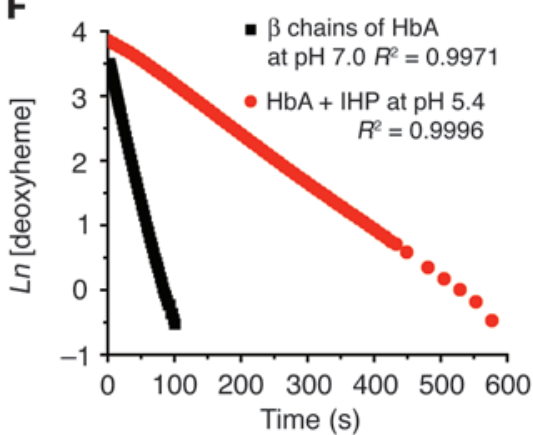

Figure 3

Rate of nitrite reductase reaction and $\mathrm{NO}$ gas formation is under allosteric control. (A) Progress of the anaerobic reaction of $\mathrm{Mb}(50 \mu \mathrm{M}$ heme) and $\mathrm{Hb}(50 \mu \mathrm{M}$ heme) with nitrite $(10 \mathrm{mM}$ with $\mathrm{Hb}$ and $2.5 \mathrm{mM}$ with $\mathrm{Mb}$ in heme concentrations) monitored spectrophotometrically by metHb formation at $630 \mathrm{~nm}$. (B) First order fits for $\mathrm{Mb}$ and non-first order behavior of tetrameric $\mathrm{Hb}$ (fits of natural log of deoxyheme concentration for the same reactions shown in A). (C) Simultaneous measurement of NO gas by chemiluminescence during the course of the reaction shown in A. Inset shows the instantaneous rate of deoxyheme consumption over the course of the reaction, obtained from spectral deconvolution. (D) The time to peak NO production measured by chemiluminescence for the reaction of nitrite $(10 \mathrm{mM})$ with $\mathrm{Hb}(50 \mu \mathrm{M}$ heme) with varying saturation $(0-75 \%)$ of carbon monoxide. $\% \mathrm{HbCO}$, percentage of $\mathrm{Hb}$ that is saturated with carbon monoxide. (E) Reaction progress for $\beta$ chains of $\mathrm{HbA}$ (locked in R state tetramer; $35 \mu \mathrm{M}$ heme reacted with $0.5 \mathrm{mM}$ nitrite at $\mathrm{pH} 7.0$ ) and IHP-treated Hb (locked into T state tetramer; $50 \mu \mathrm{M}$ heme reacted with $2.5 \mathrm{mM}$ nitrite at $\mathrm{pH}$ 6.4) was monitored by the rate of deoxyheme consumption. (F) First-order fits for $\beta$ chains of $\mathrm{HbA}$ at $\mathrm{pH} 7.0$ and for IHP-treated $\mathrm{Hb}$ at $\mathrm{pH} 6.4$ for conditions in $\mathbf{E}$ showing that the deviation from first order requires an allosteric structural transition of the $\mathrm{Hb}$ tetramer (fits of natural log of deoxyheme concentration for the same reactions shown in $\mathbf{E}$ ). 

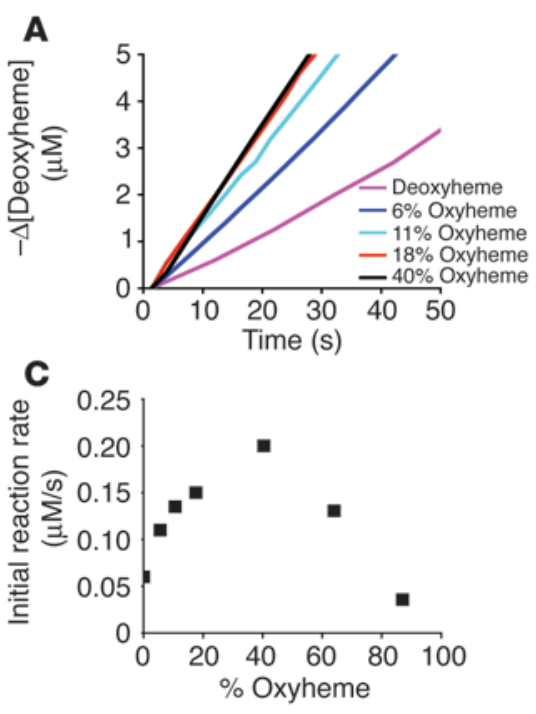

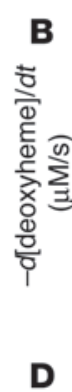

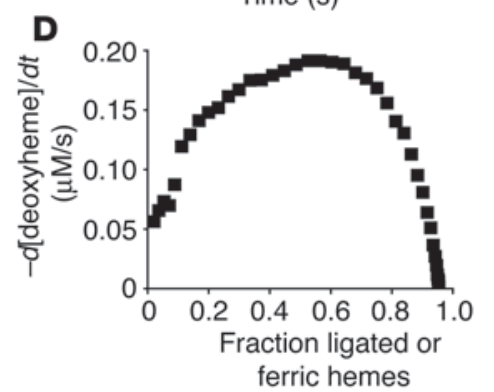

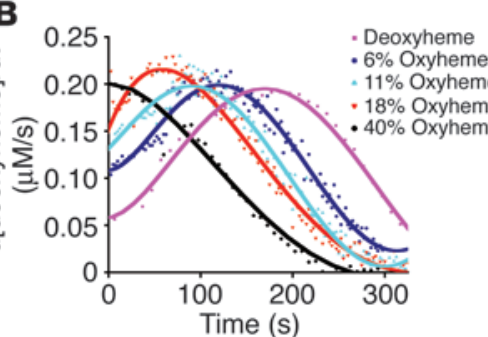

\section{Figure 4}

Maximal rates for nitrite reduction to NO occurs around the $\mathrm{Hb} \mathrm{P}_{50}$. (A) The negative of the change in deoxyheme concentration (obtained by spectral deconvolution) over time during the reaction of nitrite $(10 \mathrm{mM})$ with partially oxygenated $(0-40 \%) \mathrm{Hb}(50 \mu \mathrm{M}$ total heme). (B) Instantaneous rate of deoxyheme consumption over the course of the experiment described in A. (C) Initial rate (intercept of the polynomial fitting in $\mathbf{B}$ at $\mathbf{0}$ seconds) of reaction for the conditions described above plotted as a function of initial oxygen saturation. (D) The instantaneous rate of deoxyheme consumption versus fraction ligated or oxidized ferric hemes (relative to total heme: deoxy-, met-, and iron-nitrosyl-Hb) during the course of the anaerobic reaction of nitrite $(10 \mathrm{mM})$ with deoxyheme $(50 \mu \mathrm{M})$.
Doyle, and that the reaction appeared to obey first-order kinetics $(19,30)$. However, in the Luchsinger study, the initial deoxyHb preparation contained approximately $10 \%$ metHb; this contamination produces $\mathrm{R}$ state catalysis of this reaction. A second study by Huang et al. demonstrated the effects of metHb and R state stabilization on increasing the reaction rate and mathematically modeled the nitrite-deoxyHb reaction, producing results that are consistent with our proposed allosteric autocatalytic reaction (14).

Maximal NO generation near the Hb $P_{50}$ provides Hb with oxygen-sensor and NO-donor properties. The above considerations suggest that the rate of the nitrite-deoxy $\mathrm{Hb}$ reaction is maximal at $40-60 \%$ oxygen saturation because of the balance between the deoxyheme concentration, which is required for nitrite binding, and the greater reductive ability of the $\mathrm{R}$ state deoxyheme, which is required for the reduction of nitrite. To confirm this, we next measured NO gas formation during the nitrite- $\mathrm{Hb}$ and nitrite- $\mathrm{Mb}$ reaction and tested to see whether NO generation is under allosteric and proton-linked control. In these experiments, deoxygenated $\mathrm{Mb}, \mathrm{Hb}$, and partially carbon monoxide- or oxygen-bound $\mathrm{Hb}$ preparations were reacted with excess nitrite anaerobically, while constant stirring and purging with helium occurred (except for partial oxyHb reactions). The purged gas traveled in-line into a chemiluminescent $\mathrm{NO}$ gas analyzer for detection of NO. The reaction was monitored simultaneously by visible absorbance spectrophotometry and the rate of reaction measured as the rate of deoxyheme consumption.

$\mathrm{Mb}(50 \mu \mathrm{M})$ is locked in $\mathrm{R}$ state conformation and has a low heme reduction potential. As expected, the reaction with excess nitrite $(2.5 \mathrm{mM})$ exhibited a rapid rate with first-order exponential decay as the deoxyheme sites were consumed in the reaction (Figure 3, A and B). Simultaneously measured NO gas generation followed similar firstorder kinetics with a rapid initial rate of $\mathrm{NO}$ formation that decreased exponentially (consistent with a first-order process; Figure 3C). In contrast, tetrameric $\mathrm{Hb}$ exhibited a more sigmoidal reaction profile, thus deviating from first-order behavior, and demonstrated a maximal rate of NO generation in the middle of the reaction when the balance between the number of deoxyhemes and their reductive potential was optimal (Figure 3, A-C). Since the ligation of CO to heme produces the $\mathrm{R}$ state conformation of $\mathrm{Hb}$, we equilibrated deoxyHb with varying concentrations of $\mathrm{CO}$ and reacted this par- tial carboxyHb mixture $(0,50$, and $75 \%)$ with nitrite to evaluate the effect of $\mathrm{R}$ state character on the rate of $\mathrm{NO}$ generation. As shown in Figure 3D, the time to peak $\mathrm{NO}$ production decreased as carboxyHb saturation increased from 0 to $75 \%$, corresponding with increasing $\mathrm{R}$ state character at the beginning of the reaction. $\beta$ chains of $\mathrm{HbA}$ were locked in R state tetrameric conformation, and IHP-treated $\mathrm{HbA}$ at low $\mathrm{pH}$ was locked in $\mathrm{T}$ state tetrameric conformation. The rate of deoxyheme consumption for both of these $\mathrm{Hb}$ species, similar to that for $\mathrm{Mb}$ (as shown in Figure 3C inset), was fast initially and then slowed down exponentially as their reaction with nitrite progressed (Figure 3E). Together with the Mb's linear first-order fit, shown in Figure 3B, the first-order fits for $\beta$ chains and IHP-treated $\mathrm{Hb}$ demonstrate that in the absence of an allosteric structural transition of the $\mathrm{Hb}$ tetramer, the reaction follows first-order kinetics (Figure 3F). We also confirmed the more rapid rate of reaction for the R state $\beta$ chains of $\mathrm{Hb}$ compared with the slower rate for the $\mathrm{T}$ state $\mathrm{HbA}$ in the presence of IHP at low $\mathrm{pH}$.

Maximal nitrite reductase rate is observed at $40-60 \%$ oxy $\mathrm{Hb}$ saturation. We next added nitrite to $\mathrm{Hb}$ with a range of initial oxyHb saturations and monitored the initial rate of the nitrite reductase reaction by deconvoluting the deoxyHb spectra and observing the rate of disappearance of deoxyheme. This allowed for the specific measurement of the nitrite reductase reaction independent of additional reactions between nitrite and oxyheme. These reactions were performed in anaerobic cuvettes with additions of oxygen to achieve the measured oxygen saturations shown in Figure 4. Consistent with allosteric modulation of the nitrite reductase reaction, the initial rate of the reaction increased as the initial oxyHb concentration increased and reached a maximal rate at $40-60 \% \mathrm{Hb}$ oxygen saturation (Figure 4, A-C). We reexamined the anaerobic reaction of nitrite with deoxyHb by plotting the instantaneous reaction rate at each time point during the course of the reaction versus the fraction of total hemes ligated with $\mathrm{NO}$ and oxidized to metHb. This revealed a similar effect: a maximal nitrite reductase rate at approximately $40-60 \% \mathrm{Hb}$ ligation (in this case metheme and iron-nitrosyl acting as R state modifiers; Figure 4D).

$\mathrm{pH}$ sensor chemistry is mediated by nitrite protonation and redox Bobr effect. Because the nitrite reduction reaction described in Reaction 1 requires a proton, increasing concentration of protons would be 

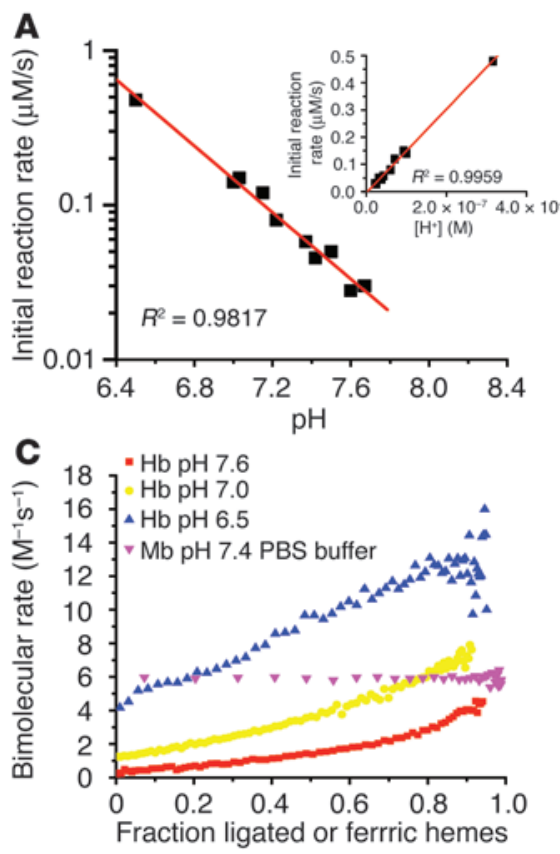

B

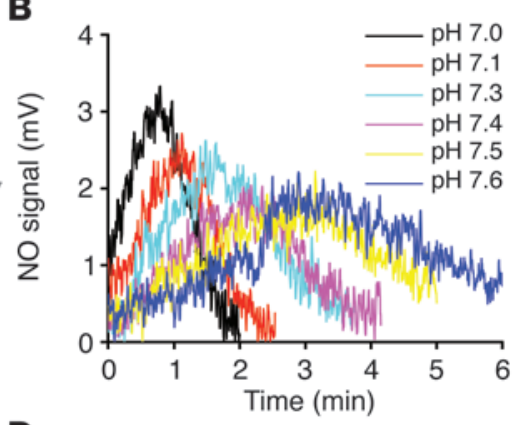

D

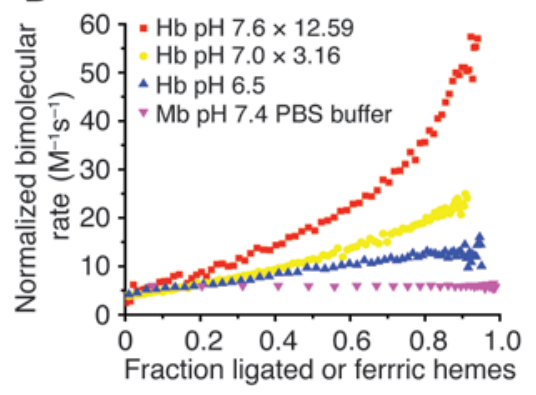

\section{Figure 5}

Effect of $\mathrm{pH}$ on the nitrite reductase reaction. (A) The initial rate (found by the polynomial fitting of the rate of deoxyheme consumption over fraction ligated) of the reaction of nitrite $(2.5 \mathrm{mM})$ with deoxyHb (45 $\mu \mathrm{M}$ heme) at different $\mathrm{pH}$ values in $0.01 \mathrm{M}$ phosphate buffer. Inset shows the initial rate plotted against concentration of proton. (B) NO gas measured by chemiluminescence from the reactions shown in A. (C) The bimolecular rate of the reaction of nitrite with deoxyHb in phosphate buffer at $\mathrm{pH} 7.6,7.0$, and 6.5 and deoxymyoglobin in PBS buffer at $\mathrm{pH} 7.4$ over heme ligand and oxidation states. (D) Correction factors 12.59 and 3.16 (given by $10^{\mathrm{pH}-6.5}$ ) were multiplied by the bimolecular rates at $\mathrm{pH} 7.6$ and 7.0, respectively (shown in C) to eliminate the contribution of changing proton concentrations to the bimolecular rate. expected to accelerate this reaction by the inverse log of $-\Delta \mathrm{pH}$ (i.e., as $\mathrm{pH}$ decreases from 7.6 to 6.5 the rate should increase by $10^{-(\Delta \mathrm{pH})}=10^{-(6.5-7.6)}=10^{1.1}$ or by 12.59 fold $)$. However, if our allosteric model of nitrite reduction is correct, an additional opposing "redox (oxidation) Bohr effect" of decreasing $\mathrm{pH}$ on the stabilization of the $\mathrm{T}$ state tetramer would be expected to increase the heme redox potential and slow down the reaction. Analogous to the oxygen Bohr effect of $\mathrm{Hb}(31,32)$, the relationship between redox potential of ferrihemes and $\mathrm{pH}$ is linear within the physiologic $\mathrm{pH}$ range, such that a 1 -unit decrease in $\mathrm{pH}$ is accompanied by a $60 \mathrm{mV}$ increase in $\mathrm{E}_{1 / 2}(33-36)$. To characterize these competing chemistries, establish whether the nitrite reductase activity of $\mathrm{Hb}$ has $\mathrm{pH}$ sensor properties, and provide additional confirmation of an allosteric model, we evaluated the effect of $\mathrm{pH}$ on this reaction using $0.01 \mathrm{M}$ phosphate buffer adjusted to the corresponding $\mathrm{pH}$. Consistent with the inverse log increase in rate $\left(10^{-\Delta \mathrm{pH}}\right)$ due to more nitrite protonation, decreasing $\mathrm{pH}$ within the physiological range $(\mathrm{pH}$ 6.4-7.8) dramatically increased the initial rate of the reaction (measured by spectral deconvolution, $R^{2}=0.98$ for linear fit of $\log _{10}$ [initial rate] vs. $\mathrm{pH}$ ) and the rate of NO gas generation from nitrite (measured by chemiluminescence) (Figure 5, A and B).

It is important to recognize that the initial reaction rate could not be affected by the redox Bohr effect because all of the $\mathrm{Hb}$ was already fully deoxygenated and in $\mathrm{T}$ state at the beginning of the reaction. This is clearly evidenced by the exact inverse log increase in initial reaction rate as $\mathrm{pH}$ decreased (Figure 5A) or, equivalent$\mathrm{ly}$, the linear increase in the initial reaction rate as proton concentration increased (Figure 5A, inset). The initial reaction rate increased as the proton concentration increased, and the linear fit extended through the zero point, demonstrating that protonation is required for the nitrite and deoxyHb reaction (Figure 5A, inset). However, we hypothesized that as the reaction proceeded, the redox Bohr effect would slow the transition from T-to-R by stabilizing the $\mathrm{T}$ state. We therefore compared the "instantaneous" bimolecular rate of the reaction at $\mathrm{pH}$ values of 7.6, 7.0, and 6.5 during the course of the reaction, over a range of heme "saturations" (i.e., data shown as the fraction of total NO-ligated or ferric hemes during the process of the anaerobic reaction of nitrite and $\mathrm{Hb}$ ). In Figure 5C, we indicate the expected large effect of decreasing $\mathrm{pH}$ on increasing the initial bimolecular rate (calculated as instantaneous reaction rate divided by the concentration of nitrite and deoxyheme), but the increase in the bimolecular rate as the $\mathrm{Hb}$ becomes fully ligated and undergoes T-to- $\mathrm{R}$ transition was reduced. This is more clearly shown by normalizing the bimolecular rates during the course of the reaction by the inverse log of $-\Delta \mathrm{pH}$ to correct for the direct proton concentration effect. In Figure 5D, we clearly show that the initial bimolecular rate is unaffected by redox Bohr effect, as all the $\mathrm{Hb}$ is in the $\mathrm{T}$ state, but as the reaction progresses, the rise in the bimolecular rate is limited at low $\mathrm{pH}$ due to the effect of redox Bohr on the stabilization of $\mathrm{T}$ state tetramer. In a physiological system, the effect of lowering $\mathrm{pH}$ on increasing the heme redox potential would be more than offset by the inverse log increase in the reaction rate and $\mathrm{pH}$-dependent exposure of more deoxyhemes for nitrite reduction.

Kinetic considerations. The chemical behavior of $\mathrm{Hb}$ as a nitrite reductase presents an elegant mechanism for oxygen sensing, as the maximal nitrite reductase activity is allosterically linked to the $\mathrm{Hb} \mathrm{P}_{50}$. In addition, this mechanism appears to address kinetic concerns over the requirement for a rapid generation of a vasodilating effector. While the bimolecular rate constant of nitrite reduction by $\mathrm{T}$ state deoxyHb is $0.12 \mathrm{M}^{-1} \mathrm{~s}^{-1}$ at $25^{\circ} \mathrm{C}$ and $\mathrm{pH} 7.4$, this bimolecular rate constant increases exponentially during T-to-R allosteric transition to approximately 50-fold at the end of the reaction (Figure $2 \mathrm{~B}$ ). Thus the rate of the $\mathrm{R}_{4}$ state $\mathrm{Hb}$ tetramer approaches that of $\mathrm{Mb}\left(6 \mathrm{M}^{-1} \mathrm{~s}^{-1}\right.$; Figure $\left.2 \mathrm{~B}\right)$. The average bimolecular rate constant during the reaction process was $0.35 \mathrm{M}^{-1} \mathrm{~s}^{-1}$, on the same order as our previously measured value of $0.47 \mathrm{M}^{-1} \mathrm{~s}^{-1}$ (11) and that found by Doyle et al. $\left(1 \mathrm{M}^{-1} \mathrm{~s}^{-1}\right)$ (19). In addition, the requirement of a proton for the reaction suggests that the rate will increase by the inverse log of $-\Delta \mathrm{pH}$. For example, in a vascular bed under physiological metabolic stress with $\mathrm{Hb}$ oxygen saturation of 
$60 \%$ at $\mathrm{pH} 7.0$ and $37^{\circ} \mathrm{C}$, the bimolecular rate of nitrite reduction to $\mathrm{NO}$ would be $4.4 \mathrm{M}^{-1} \mathrm{~s}^{-1}$. We and others have recently reported that red blood cells have $300 \mathrm{nM}$ intracellular nitrite in steady state and that these levels are controlled across a narrow physiological range (37). Indeed, blood levels of nitrite appear to be conserved across species with uptake and utilization by the erythrocyte under oxygen- and $\mathrm{pH}$-dependent control $(18,38-40)$. As Hb deoxygenates in a metabolically active vascular bed and reaches an oxygen saturation of $60 \%$ at $\mathrm{pH} 7.0$ and $37^{\circ} \mathrm{C}$, the bimolecular rate of nitrite reduction to $\mathrm{NO}$ would be at $4.4 \mathrm{M}^{-1} \mathrm{~s}^{-1}$ and the $300 \mathrm{nM}$ nitrite would react with the $12 \mathrm{mM}$ intracellular deoxyheme to form $10.6 \mathrm{nM}$ NO per second, a kinetic result consistent with our prior physiological observations (11). While we have shown that injections of nitrite into solutions of red cell and $\mathrm{Hb}$ solutions generates $\mathrm{NO}$ gas, additional studies are required to evaluate how $\mathrm{NO}$ can escape the erythrocyte and avoid autocapture by intracellular $\mathrm{Hb}$ (discussed more fully in Discussion).

\section{Discussion}

Physiological implications for bypoxic vasodilation. Hypoxic vasodilation requires oxygen sensing and the rapid elaboration of a vasodilating mediator that modulates the microvascular resistance of arterioles. Consistent with an oxygen-sensor set point around $\mathrm{Hb}$ $\mathrm{P}_{50}$, classical physiological studies of hypoxic vasodilation consistently reveal a threshold for this response of around $40-60 \% \mathrm{Hb}-$ oxygen saturation $\left(\mathrm{PO}_{2}\right.$ of $\left.20-40 \mathrm{~mm} \mathrm{Hg}\right)(4,22)$. Accumulating data obtained from measurements of microvascular longitudinal oxygen and $\mathrm{Hb}$-oxygen saturation gradients suggest that arteriolar oxygen tension decreases as blood flows through A1 to A4 caliber arterioles. This drop is substantial in skeletal muscle, resulting in A4 level arteriolar $\mathrm{PO}_{2}$ values approaching $20 \mathrm{~mm} \mathrm{Hg}$ and $\mathrm{Hb}$ saturations of less than $40 \%$ (recently reviewed in ref. 41). These decreases in oxygen have been attributed to direct oxygen delivery from arterioles, oxygen consumption by endothelium and smooth muscle, and counter-current oxygen exchange with the venous system. The latter has been reported to deliver $\mathrm{CO}_{2}$ to arterioles, an effect that lowers the Hb-oxygen affinity via the Bohr effect. These oxygen delivery profiles indicate that $\mathrm{Hb}$ desaturates below $50 \%$ within the skeletal muscle resistance microvasculature, a process that would also maximize Hb's nitrite reductase activity within A4 arterioles. In the heart and brain, where most of the oxygen is delivered from the capillary bed, a retrograde propagation of the vasodilator signal has been invoked to explain feedback vasodilation from the hypoxic tissue to resistance arterioles $(42,43)$.

We recognize that it is likely that hypoxic vasodilation, like endothelium-dependent blood flow regulation, is overbuilt, with multiple overlapping mechanisms that ensure adequate oxygen delivery to respiring tissues. Erythrocyte- and Hb-dependent nitrite reduction to NO (11) and ATP (6-8) release would provide vasodilation at oxygen tensions from 40 to $15 \mathrm{~mm} \mathrm{Hg}$. Additional mechanisms for hypoxic vasodilation likely overlap with the erythrocyte systems, including production of adenosine, prostaglandins, NO, and endothelium-derived hyperpolarizing factor from tissue, as well as sympathetic feedforward vasodilation (recently reviewed in ref. 4).

Below $10 \mathrm{~mm} \mathrm{Hg}$ oxygen tension, direct nitrite reduction to $\mathrm{NO}$ by nonenzymatic disproportionation (acidic reduction similar to that reported in the stomach) (44-46) and enzymatic reduction by xanthine oxidoreductase (47-49) may contribute to hypoxic vasodilation and anaerobic NO formation. Additionally, the "burst"
$\mathrm{NO}$ formation observed for $\mathrm{Mb}$ (Figure 4A) is of particular interest and suggests that decreases in $\mathrm{PO}_{2}$ to below 2-4 mm Hg, as occurs during exercise, in ischemia, and in highly metabolic tissue, would be associated with a rapid conversion of tissue nitrite (approaching levels of $20 \mu \mathrm{M}$; ref. 37) to NO. This nitrite reductase activity of $\mathrm{Mb}$ (or cytoglobin and neuroglobin) might participate in the modulation of tissue mitochondrial respiration and limitation of ischemia-reperfusion injury during extremes of exercise or pathological vasoocclusion $(50,51)$.

NO export from the erythrocyte? A major challenge for a role for nitrite- $\mathrm{Hb}$ reactions in the control of hypoxic vasodilation is the kinetics of $\mathrm{NO}$ reactions with vicinal deoxy- and oxyHb, which should limit NO diffusion out of the erythrocyte. However, our earlier studies reveal that physiological concentrations of nitrite vasodilate aortic rings only in the presence of deoxyHb or deoxygenated erythrocytes and that near physiological concentrations of nitrite result in vasodilation in the human forearm (11). Indeed, kinetic predictions would suggest that NO should not escape into the head space for gas-phase detection in the current study illustrated in Figures 3C and 5B. While the solution to this paradox is not yet clear, we recognize that biology may overcome such kinetic constraints. For example, a membrane-associated nitrite reductase metabolon with deoxyHb and metHb, anion exchange protein, carbonic anhydrase, aquaporin, and rhesus channels could bring together nitrite, proton, deoxyheme, and highly hydrophobic channels that could serve to concentrate the lipophilic NO at the membrane complex (52). Indeed, the heme pocket distal histidine may donate a proton to the reaction, an effect analogous to the proton donation by aspartate in the bacterial nitrite reductase enzyme (53). This histidine proton donation to nitrite would serve to both position and stabilize nitrite in the heme pocket and accelerate the reaction by forming nitrous acid.

Because of the potency of NO (50\% effectivev concentration [EC $\left.\mathrm{E}_{50}\right]$ of only $1-5 \mathrm{nM}$ ) and because flow is proportional to the radius to the fourth power, very little NO escape is required for vasodilation. We are currently exploring other potential intermediates that may form in the nitrite deoxyHb reaction including $\mathrm{H}_{2} \mathrm{NO}_{2}$ (hydrated NO), $\mathrm{HNO}_{2}{ }^{-}, \mathrm{NO}_{2}{ }^{2-}$ (described by Doyle; ref. 19), $\mathrm{NO}, \mathrm{ONOO}^{-}$, and $\mathrm{N}_{2} \mathrm{O}_{3} \cdot \mathrm{N}_{2} \mathrm{O}_{3}$ formation by reductive nitrosylation catalyzed by nitrite has recently been characterized by Fernandez and Ford (29). Many of these intermediates would be stabilized in hydrophobic channels $\left(\mathrm{H}_{2} \mathrm{NO}_{2}, \mathrm{~N}_{2} \mathrm{O}_{3}\right.$, and $\left.\mathrm{NO}\right)$ while others would be stabilized in anion channels, such as the anion exchange protein $\left(\mathrm{HNO}_{2}{ }^{-}, \mathrm{ONOO}^{-}\right.$, and $\left.\mathrm{NO}_{2}{ }^{2-}\right)$. A maximal rate of $\mathrm{NO}$ formation near the $\mathrm{Hb} \mathrm{P}_{50}$ may also lead to reactions with superoxide $\left(\mathrm{O}_{2}^{-}\right)$, known to form from $\mathrm{Hb}$ auto-oxidation at $\mathrm{P}_{50}$ (54). Diffusion limited $\mathrm{NO}_{-} \mathrm{O}_{2}^{-}$reactions can generate $\mathrm{ONOO}^{-}$and $\mathrm{N}_{2} \mathrm{O}_{3}$, which have the potential to nitrosate low-molecular-weight thiols in the heme pocket (55).

In conclusion, these data reveal 2 novel properties of the $\mathrm{Hb}$ molecule: first, the nitrite reductase activity of $\mathrm{Hb}$ produces $\mathrm{NO}$ under allosteric control; and second, the rate of nitrite reduction to $\mathrm{NO}$ is maximal at $40-60 \% \mathrm{Hb}$-oxygen saturation. These 2 properties provide a biochemical mechanism that could link allosteric oxygen sensing to vasodilation. These data suggest that $\mathrm{Hb}$ oxygen saturation and quaternary structure rather than tissue $\mathrm{PO}_{2}$ act as oxygen sensors for hypoxic vasodilation and that the vasodilation effector is $\mathrm{NO}$, generated by a nitrite reductase activity of $\mathrm{Hb}$. Understanding this chemistry should allow for therapeutic targeted NO delivery to specific tissues under hypoxic stress using nitrite solutions. 


\section{Methods}

Reagents and $\mathrm{Hb}$ preparations. All reagents were purchased from SigmaAldrich, except mutant $\mathrm{Hb}$, which was provided by C. Ho. Unless otherwise indicated, $\mathrm{Hb}$ solutions and reactions were performed using phosphatebuffered saline, $\mathrm{pH} 7.4$, at room temperature. Isolated $\beta$ chains of $\mathrm{HbA}$ (tetramer) were prepared by C. Ho. Normal human adult $\mathrm{Hb}$ was prepared by hypotonically lysing washed erythrocytes, discarding the membrane fractions, and storing the hemolysate at $-80^{\circ} \mathrm{C}$ as previously described (56). The $\mathrm{Hb}$ was either dialyzed or passed through a size exclusion column washed with buffer corresponding to the particular experiment. NEMmodified $\mathrm{HbA}$ was prepared by incubating $200-\mu \mathrm{M}$ HbA with $10-\mathrm{mM}$ NEM for 1 hour in PBS buffer at $\mathrm{pH} 7.4$ in equilibrium with room air and room temperature. For IHP-bound $\mathrm{Hb}$, the $\mathrm{pH}$ of IHP solution was adjusted to 7.4 prior to addition to deoxyHb in a 5 to 1 ratio. Excess NEM or IHP was removed by sephadex G25 column (Amersham Biosciences). The oxygen saturation of the $\mathrm{Hb}$ solution was measured by visible absorption spectroscopy (HP8453 UV-Vis spectrophotometer; Hewlett-Packard). The concentration and percentage of each heme species was analyzed by deconvoluting the spectrum into components from basis spectra of $\mathrm{Hb}$ composed of oxyHb, deoxyHb, iron-nitrosyl- $\mathrm{Hb}$, carboxyHb, metHb and metHb-nitrite, using a least squares method similar to that previously described (55). CarboxyHb was included in the analysis only when carboxyHb was added to the reaction mixture. Both metHb and metHb-nitrite have significant absorption at $630 \mathrm{~nm}$, and their sum was reported as the total amount of metHb or ferric hemes.

Simultaneous measurement of the nitrite reaction with Hb by visible absorption spectroscopy and $N O$ gas detection by chemiluminescence. In these experiments, $50-\mu \mathrm{M}$ deoxygenated $\mathrm{Mb}, \mathrm{Hb}$, and $\mathrm{Hb}$ preparations partially ligated with carbon monoxide were reacted with excess nitrite $(10 \mathrm{mM}, 2.5 \mathrm{mM}$ with $\mathrm{Mb}$ ) anaerobically in a $25-\mathrm{ml}$ flask for NO measurement. During this time, constant stirring and head-space purging with helium were performed (note that the solution is not purged; only the head space gas is entrained). The purged gas traveled in-line through the head space of the flask containing $5 \mathrm{ml}$ of reaction mixture into a chemiluminescent $\mathrm{NO}$ gas analyzer (Sievers NO analyzer; GE Analytical Instruments) for detection of NO. The reaction was monitored simultaneously in a 1-cm pathlength glass cuvette under positive helium pressure for spectral measurement by visible absorbance spectrophotometry at room temperature using an HP 8953 UV-Vis spectrophotometer (Hewlett-Packard). Reaction progress was monitored by the change of absorption at $630 \mathrm{~nm}$. Concentrations in deoxyheme, oxyheme, iron-nitrosyl-heme, and metheme at any time point were derived through spectral deconvolution. The instantaneous reaction rate was measured as the instantaneous rate of deoxyheme consumption (negative change of deoxyheme concentration with respect to time interval). Bimolecular rate (or bimolecular rate constant in the case of $\mathrm{Mb}$ ) of the reaction between deoxyheme and nitrite was obtained by the instantaneous reaction rate divided by the concentration of nitrite and deoxyheme at that instant. Note that all of the UV-vis experiments were performed in anaerobic cuvettes without purging. We applied positive helium pressure without a channel for gas escape, as this prevents oxygen leaks into the system. Only the NO gas formation experiments are performed with head space gas collection (Figures $3 \mathrm{C}$ and $5 \mathrm{~B}$ ).

EPR spectroscopy with spectral deconvolution. EPR spectroscopy was conducted at temperatures of $132 \mathrm{~K}$ with a Bruker $4111 \mathrm{VT}$ variable temperature unit and ESR-ER-200 D spectrometer set (Bruker BioSpin GmbH) at 9.43 $\mathrm{GHz}$ microwave frequency, $10 \mathrm{~mW}$ microwave power, 5 Gauss modulation amplitude, a time constant of $100 \mathrm{~ms}$, and a collection time of 100 seconds for each scan. The EPR spectrum for iron-nitrosyl-Hb was deconvoluted to obtain the percentage of each species of nitrosyl-heme (penta- and hexacoordinate $\alpha$ heme and hexacoordinate $\beta$-nitrosyl-heme) using basis spectra as described previously (26).

\section{Acknowledgments}

We acknowledge the careful work of Vidhya Annavajhhala, Catherine E. Cushenberry, and Peter Grant in support of this project. This work was supported by the Intramural Division of the NIH and partially supported by NIH grants HL58091 (to D. Kim-Shapiro) and GM55792 (to N. Hogg). EPR spectrometry was facilitated by a grant from the North Carolina Biotechnology Center (2003IDG-1013 to D. Kim-Shapiro).

Received for publication February 3, 2005, and accepted in revised form May 24, 2005.

Address correspondence to: Mark T. Gladwin, NIH, Building 10Clinical Research Center, Room 5-5140, 10 Center Drive, Bethesda, Maryland 20892-1662, USA. Phone: (301) 435-2310; Fax: (301) 402-1213; E-mail: mgladwin@mail.nih.gov.
1. Gremels, H., and Starling, E.H. 1926. On the influence of hydrogen ion concentration and of anoxaemia upon the heart volume. J. Physiol. (Lond). 61:297-304.

2. Hilton, R., and Eichholtz, F. 1925. The influence of chemical factors on the coronary circulation. J. Physiol. (Lond). 59:413-425.

3. Tune, J.D., Richmond, K.N., Gorman, M.W., and Feigl, E.O. 2001. K(ATP)(+) channels, nitric oxide, and adenosine are not required for local metabolic coronary vasodilation. Am. J. Physiol. Heart Circ. Physiol. 280:H868-H875.

4. Tune, J.D., Gorman, M.W., and Feigl, E.O. 2004 Matching coronary blood flow to myocardial oxygen consumption. J. Appl. Physiol. 97:404-415.

5. Ellsworth, M.L. 2000. The red blood cell as an oxygen sensor: what is the evidence [review]? Acta Physiol. Scand. 168:551-559.

6. Dietrich, H.H., Ellsworth, M.L., Sprague, R.S., and Dacey, R.G., Jr. 2000. Red blood cell regulation of microvascular tone through adenosine triphosphate. Am. J. Physiol. Heart Circ. Physiol. 278:H1294-H1298.

7. Ellsworth, M.L., Forrester, T., Ellis, C.G., and Dietrich, H.H. 1995. The erythrocyte as a regulator of vascular tone. Am. J. Physiol. 269:H2155-H2161.

8. Sprague, R.S., Ellsworth, M.L., Stephenson, A.H., and Lonigro, A.J. 1996. ATP: the red blood cell link to $\mathrm{NO}$ and local control of the pulmonary circulation. Am. J. Physiol. 271:H2717-H2722.

9. Jia, L., Bonaventura, C., Bonaventura, J., and Stamler, J.S. 1996. S-nitrosohaemoglobin: a dynamic activity of blood involved in vascular control. Nature. 380:221-226.

10. Stamler, J.S., et al. 1997. Blood flow regulation by S-nitrosohemoglobin in the physiological oxygen gradient. Science. 276:2034-2037.

11. Cosby, K., et al. 2003. Nitrite reduction to nitric oxide by deoxyhemoglobin vasodilates the human circulation. Nat. Med. 9:1498-1505.

12. Hunter, C.J., et al. 2004. Inhaled nebulized nitrite is a hypoxia-sensitive $\mathrm{NO}$-dependent selective pulmonary vasodilator. Nat. Med. 10:1122-1127.

13. Nagababu, E., Ramasamy, S., Abernethy, D.R., and Rifkind, J.M. 2003. Active nitric oxide produced in the red cell under hypoxic conditions by deoxyhemoglobin-mediated nitrite reduction. J. Biol. Chem. 273:46349-46356.

14. Huang, K.T., et al. 2005. The reaction between nitrite and deoxyhemoglobin: reassessment of reaction kinetics and stoichiometry. J. Biol. Chem. doi:10.1074/jbc.M501496200.

15. Ignarro, L.J., and Gruetter, C.A. 1980. Requirement of thiols for activation of coronary arterial guanylate cyclase by glyceryl trinitrate and sodium nitrite: possible involvement of S-nitrosothiols. Biochim. Biophys. Acta. 631:221-231.

16. Furchgott, R.F., and Bhadrakom, S. 1953. Reactions of strips of rabbit aorta to epinephrine, isopropylarterenol, sodium nitrite and other drugs. J. Pharmacol. Exp. Ther. 108:129-143.

17. Arnold, W.P., Mittal, C.K., Katsuki, S., and Murad, F. 1977. Nitric oxide activates guanylate cyclase and increases guanosine $3^{\prime}: 5^{\prime}$-cyclic monophosphate levels in various tissue preparations. Proc. Natl. Acad. Sci. U. S. A. 74:3203-3207.

18. Gladwin, M.T., et al. 2000. Relative role of heme nitrosylation and beta -cysteine 93 nitrosation in the transport and metabolism of nitric oxide by hemoglobin in the human circulation. Proc. Natl. Acad. Sci. U. S. A. 97:9943-9948.

19. Doyle, M.P., Pickering, R.A., DeWeert, T.M., Hoekstra, J.W., and Pater, D. 1981. Kinetics and mechanism of the oxidation of human deoxyhemoglobin by nitrites. J. Biol. Chem. 256:12393-12398.

20. Brooks, J. 1937. The action of nitrite on haemoglobin in the absence of oxygen. Proc. R. Soc. Med. 123:368-382.

21. Hsia, C.C. 1998. Respiratory function of hemoglobin. 
N. Engl. J. Med. 338:239-247.

22. Ross, J.M., Fairchild, H.M., Weldy, J., and Guyton, A.C. 1962. Autoregulation of blood flow by oxygen lack. Am. J. Physiol. 202:21-24.

23. Doyle, M.P., and Hoekstra, J.W. 1981. Oxidation of nitrogen oxides by bound dioxygen in hemoproteins. J. Inorg. Biochem. 14:351-358.

24. Yonetani, T., Tsuneshige, A., Zhou, Y., and Chen, X. 1998. Electron paramagnetic resonance and oxygen binding studies of alpha- nitrosyl hemoglobin. A novel oxygen carrier having no-assisted allosteric functions. J. Biol. Chem. 273:20323-20333.

25. Hille, R., Olson, J.S., and Palmer, G. 1979. Spectral transitions of nitrosyl hemes during ligand binding to hemoglobin. J. Biol. Chem. 254:12110-12120.

26. Xu, X., et al. 2002. Effects of iron nitrosylation on sickle cell hemoglobin solubility. J. Biol. Chem. 277:36787-36792.

27. Taboy, C.H., Faulkner, K.M., Kraiter, D., Bonaventura, C., and Crumbliss, A.L. 2000. Concentrationdependent effects of anions on the anaerobic oxidation of hemoglobin and myoglobin. J. Biol. Chem. 275:39048-39054.

28. Bonaventura, C., et al. 2002. Heme redox properties of S-nitrosated hemoglobin A0 and hemoglobin S: implications for interactions of nitric oxide with normal and sickle red blood cells. J. Biol. Chem. 277:14557-14563.

29. Fernandez, B.O., Lorkovic, I.M., and Ford, P.C. 2003. Nitrite catalyzes reductive nitrosylation of the water-soluble Ferri-Heme model Fe(III)(TPPS) to $\mathrm{Fe}(\mathrm{II})(\mathrm{TPPS})(\mathrm{NO})$. Inorg. Chem. 42:2-4.

30. Luchsinger, B.P., et al. 2005. Assessments of the chemistry and vasodilatory activity of nitrite with hemoglobin under physiologically relevant conditions. J. Inorg. Biochem. 99:912-921.

31. Bohr, C., Hasselbalch, K., and Krogh, A. 1904. Ueber einen in biologischer Beziehung wichtigen Einfluss, den die Kohlensaeurespannung des Blutes auf dessen Sauerstoffbindung ubt. Skand. Arch. Physiol. 16:402-412.

32. Perutz, M.F. 1970. Sterochemistry of cooperative effects in haemoglobin. Nature. 228:726-739.

33. Hoffman, B.M., and Bull, C. 1976. Linearity of the hemoglobin oxidation bohr effect. Proc. Natl. Acad.
Sci. U. S. A. 73:800-803.

34. Brunori, M., Wyman, J., Antonini, E., and RossiFanelli, A. 1965. Studies on the oxidation-reduction potentials of heme proteins. V. The oxidation Bohr effect in normal human hemoglobin and human hemoglobin digested with carboxypeptidase A. J. Biol. Chem. 240:3317-3324.

35. Antonini, E., et al. 1964. Studies on the oxidationreduction potentials of heme proteins. I. Human hemoglobin. J. Biol. Chem. 239:907-912.

36. Taylor, J.F., and Hastings, A.B. 1939. Oxidationreduction potentials of the methemoglobin-hemoglobin system. J. Biol. Chem. 131:649-662.

37. Dejam, A., et al. 2005. Erythrocytes are the major intravascular storage sites of nitrite in human blood. Blood. doi:10.1182/blood-2005-02-0567.

38. Bryan, N.S., et al. 2004. Cellular targets and mechanisms of nitros(yl)ation: an insight into their nature and kinetics in vivo. Proc. Natl. Acad. Sci. U. S. A. 101:4308-4313.

39. Jensen, F.B., Andersen, N.A., and Heisler, N. 1987. Effects of nitrite exposure on blood respiratory properties, acid-base and electrolyte regulation in the carp (Cyprinus carpio). J. Comp. Physiol. B, Biochem. Syst. Environ. Physiol. 157:533-541.

40. Jensen, F.B., Koldkjaer, P., and Bach, A. 2000. Anion uptake and acid-base and ionic effects during isolated and combined exposure to hypercapnia and nitrite in the freshwater crayfish, Astacus astacus. J. Comp. Physiol. B, Biochem. Syst. Environ. Physiol. 170:489-495.

41. Tsai, A.G., Johnson, P.C., and Intaglietta, M. 2003. Oxygen gradients in the microcirculation. Physiol. Rev. 83:933-963.

42. Segal, S.S., Damon, D.N., and Duling, B.R. 1989. Propagation of vasomotor responses coordinates arteriolar resistances. Am. J. Physiol. 256:H832-H837.

43. Segal, S.S., and Duling, B.R. 1989. Conduction of vasomotor responses in arterioles: a role for cell-tocell coupling? Am. J. Physiol. 256:H838-H845.

44. Lundberg,J.O., Weitzberg, E., Cole,J.A., and Benjamin, N. 2004. Nitrate, bacteria and human health [review] [erratum 2004, 2:681]. Nat. Rev. Microbiol. 2:593-602.

45. Zweier, J.L., Wang, P., Samouilov, A., and Kuppusamy, P. 1995. Enzyme-independent formation of nitric oxide in biological tissues. Nat. Med. 1:804-809.

46. Zweier, J.L., Samouilov, A., and Kuppusamy, P. 1999. Non-enzymatic nitric oxide synthesis in biological systems. Biochim. Biophys. Acta. 1411:250-262.

47. Zhang, Z., et al. 1998. Generation of nitric oxide by a nitrite reductase activity of xanthine oxidase: a potential pathway for nitric oxide formation in the absence of nitric oxide synthase activity [erratum 1998, 251:667]. Biochem. Biophys. Res. Commun. 249:767-772.

48. Millar, T.M., et al. 1998. Xanthine oxidoreductase catalyses the reduction of nitrates and nitrite to nitric oxide under hypoxic conditions. FEBS Lett. 427:225-228.

49. Li, H., Samouilov, A., Liu, X., and Zweier, J.L. 2004. Characterization of the effects of oxygen on xanthine oxidase-mediated nitric oxide formation. J. Biol. Chem. 279:16939-16946.

50. Webb, A., et al. 2004. Reduction of nitrite to nitric oxide during ischemia protects against myocardial ischemia-reperfusion damage. Proc. Natl. Acad. Sci. U. S. A. 101:13683-13688.

51. Duranski, M.R., et al. 2005. Cytoprotective effects of nitrite during in vivo ischemia-reperfusion of the heart and liver. J. Clin. Invest. 115:1232-1240. doi:10.1172/JCI200522493.

52. Gladwin, M.T., Crawford, J.H., and Patel, R.P. 2004. The biochemistry of nitric oxide, nitrite, and hemoglobin: role in blood flow regulation [review]. Free Radic. Biol. Med. 36:707-717.

53. Tocheva, E.I., Rosell, F.I., Mauk, A.G., and Murphy, M.E. 2004. Side-on copper-nitrosyl coordination by nitrite reductase. Science. 304:867-870.

54. Balagopalakrishna, C., Manoharan, P.T., Abugo, O.O., and Rifkind, J.M. 1996. Production of superoxide from hemoglobin-bound oxygen under hypoxic conditions. Biochemistry. 35:6393-6398.

55. Espey, M.G., Thomas, D.D., Miranda, K.M., and Wink, D.A. 2002. Focusing of nitric oxide mediated nitrosation and oxidative nitrosylation as a consequence of reaction with superoxide. Proc. Natl. Acad. Sci. U. S. A. 99:11127-11132.

56. Huang, Z., et al. 2001. Nitric oxide binding to oxygenated hemoglobin under physiological conditions. Biochim. Biophys. Acta. 1568:252-260. 